\title{
Consenso | Protocolo Brasileiro para Infecções Sexualmente Transmissíveis 2020: infecção pelo vírus Zika
}

doi: 10.1590/S1679-4974202100017.esp1

\author{
Brazilian Protocol for Sexually Transmitted Infections 2020: Zika virus infection \\ Protocolo Brasileño para Infecciones de Transmisión Sexual 2020: infección por el virus Zika
}

\author{
Geraldo Duarte' - (D) orcid.org/0000-0002-1689-6142 \\ Angélica Espinosa Miranda² - (1) orcid.org/0000-0002-5556-8379 \\ Ximena Pamela Díaz Bermúdez ${ }^{3}$ - (D) orcid.org/0000-0002-3771-7684 \\ Valeria Saraceni ${ }^{4}$ - (1) orcid.org/0000-0001-7360-6490 \\ Flor Ernestina Martínez-Espinosa5 - (D) orcid.org/0000-0002-0325-3674 \\ ${ }^{1}$ Faculdade de Medicina de Ribeirão Preto, Universidade de São Paulo, Ribeirão Preto, SP, Brasil \\ ${ }^{2}$ Ministério da Saúde, Secretaria de Vigilância em Saúde, Brasília, DF, Brasil \\ ${ }^{3}$ Programa de Pós-Graduação em Saúde Coletiva, Universidade de Brasília, Brasília, DF, Brasil \\ ${ }^{4}$ Secretaria Municipal de Saúde do Rio de Janeiro, Rio de Janeiro, RJ, Brasil \\ ${ }^{5}$ Fundação Oswaldo Cruz, Instituto Leônidas e Maria Deane, Manaus, AM, Brasil
}

\section{Resumo}

Este artigo aborda as transmissões vetorial, sexual e vertical do vírus Zika, tema contemplado no Protocolo Clínico e Diretrizes Terapêuticas para Atenção Integral às Pessoas com Infecções Sexualmente Transmissíveis, publicado pelo Ministério da Saúde do Brasil em 2020. Embora no Brasil o vírus Zika seja predominantemente veiculado pelo Aedes aegypti, as vias vertical e sexual de transmissão apresentam expressiva importância para a saúde reprodutiva. A transmissão sexual demanda o uso de intervenções profiláticas específicas, incluindo o uso do preservativo masculino ou feminino, principalmente entre casais que planejam gravidez. A transmissão vertical é ligada a graves anormalidades estruturais do sistema nervoso central e ainda não há vacina e nem recursos farmacológicos conhecidos que possam preveni-la. Como a doença é predominantemente assintomática, o não cumprimento dos princípios básicos de cuidados e orientações relacionadas à dispersão da infecção transcende a gravidade dos sintomas da doença.

Palavras-chave: Vírus Zika; Infecções Sexualmente Transmissíveis; Transmissão Vertical; Microcefalia; Anormalidade Congênita; Prevenção de Doenças.

Endereço para correspondência:

Geraldo Duarte - Faculdade de Medicina de Ribeirão Preto, Universidade de São Paulo, Avenida Bandeirantes, 3900, Campus da USP, Sala 808, Ribeirão Preto, São Paulo, Brasil. CEP: 34998-900

E-mail: gduarte@fmrp.usp.br 


\section{Apresentação}

0 presente artigo está relacionado ao capítulo sobre 0 vírus Zika que compõe o Procotolo Clínico e Diretrizes Terapêuticas (PCDT) para Atenção Integral às Pessoas com Infecções Sexualmente Transmissíveis (IST), publicado pela Secretaria de Vigilância em Saúde, do Ministério da Saúde do Brasil. Para a elaboração do PCDT, foram realizadas a seleção e a análise das evidências disponíveis na literatura e discussão com um painel de especialistas. 0 referido PCDT foi aprovado pela Comissão Nacional de Incorporação de Tecnologias no Sistema Único de Saúde (Conitec) ${ }^{1}$ e atualizado pelo grupo de especialistas do PCDT em 2020.

\section{Embora no Brasil o vírus Zika seja predominantemente veiculado pelo Aedes aegypti, as vias vertical e sexual de transmissão apresentam expressiva importância para a saúde reprodutiva. A transmissão vertical causa anormalidades estruturais graves do sistema nervoso central.}

\section{Aspectos epidemiológicos}

0 vírus Zika pertence à família Flaviviridae, gênero Flavivirus, e foi isolado pela primeira vez em Uganda (África), em 1947.,3 As infecções em seres humanos foram esporádicas por cerca de meio século, antes de surgirem de forma epidêmica em algumas ilhas do Pacífico e na América do Sul. ${ }^{4}$ Nesse período de disseminação em diferentes condições mesológicas, 0 vírus desenvolveu importantes mutações, caracterizando duas linhagens diferentes, a linhagem africana e a linhagem asiática. ${ }^{5}$ Paralelamente a essas adaptações genômicas, o potencial patogênico do vírus Zika foi modificado. ${ }^{6,7}$ Atualmente, apontam-se evidências de que as formas de transmissão do vírus, entre elas a sexual, sofrem influências dessas mutações virais. ${ }^{8}$

Em abril de 2015, o vírus Zika foi identificado pela primeira vez nas Américas, sendo o primeiro caso reportado na Bahia, Brasil. Ao final de janeiro de 2016, sua circulação autóctone já havia sido relatada em mais de 20 países ou territórios nas Américas do Sul, Central e do Norte, no Caribe e em Cabo Verde, na África 0cidental. ${ }^{4}$

A evolução da incidência da infeção pelo vírus Zika no Brasil está representada na Figura 1. Pode-se observar uma importante redução dos casos após 0 pico epidêmico de 2015-2016. Nesse período, foram notificados 37.011 casos em 2015; 216.207 em 2016; 17.452 em 2017; 8.024 em 2018; 10.768 em 2019; e 3.692 até a Semana Epidemiológica 23 de 2020.9-12

As três formas mais estudadas da transmissão do vírus Zika são a transmissão vetorial, decorrente da picada do mosquito, a transmissão vertical e a transmissão sexual. ${ }^{13}$ Este artigo versa sobre as transmissões vertical e sexual (sexo vaginal, anal e oral), devido ao foco do PCDT. No Brasil a transmissão vetorial é a mais frequente. Esta se dá pela picada de artrópodes infectados, sendo o Aedes aegypti o principal vetor no país. Note-se que é o mesmo mosquito que transmite os vírus da dengue, chikungunya e febre amarela. ${ }^{14}$

A transmissão transplacentária do vírus Zika traz em seu contexto imensa preocupação decorrente do seu potencial para causar anormalidades estruturais do sistema nervoso central embrionário e fetal. Vários mecanismos são evocados para explicar como 0 vírus chega ao embrião e ao feto. Como o sinciciotrofoblasto é resistente à infecção pelo vírus Zika, ${ }^{15}$ no início da gravidez alguns mecanismos são utilizados, possibilitando a entrada do vírus na vilosidade coriônica, dentre os quais se destaca a clivagem das glicosaminas por uma proteína não estrutural do vírus (non-structural, NS1). ${ }^{16}$ Dentro da vilosidade, 0 vírus Zika infecta os macrófagos (células de Hofbauer), onde provoca intensa proliferação e hiperplasia celular. ${ }^{17,18}$

Estudos descreveram a presença de vírus Zika no sangue, sêmen, urina e saliva, sugerindo que 0 vírus também poderia ser transmitido por esses fluidos corporais, mas destacaram a raridade da ocorrência. ${ }^{19-22}$ Em localidades de elevada frequência do mosquito vetor, há dificuldade de estabelecer 0 risco atribuível à transmissão primária pela via sexual. Assim, essa via de transmissão tem maior importância e maior potencial de investigação em países onde a infecção pelo vírus Zika não seja endêmica, ${ }^{23,25}$ embora também possa ocorrer em países com transmissão ativa por artrópodes. ${ }^{26}$ Essa forma de transmissão já foi relatada em pelo menos 13 países sem transmissão por mosquito..$^{27-28}$ 


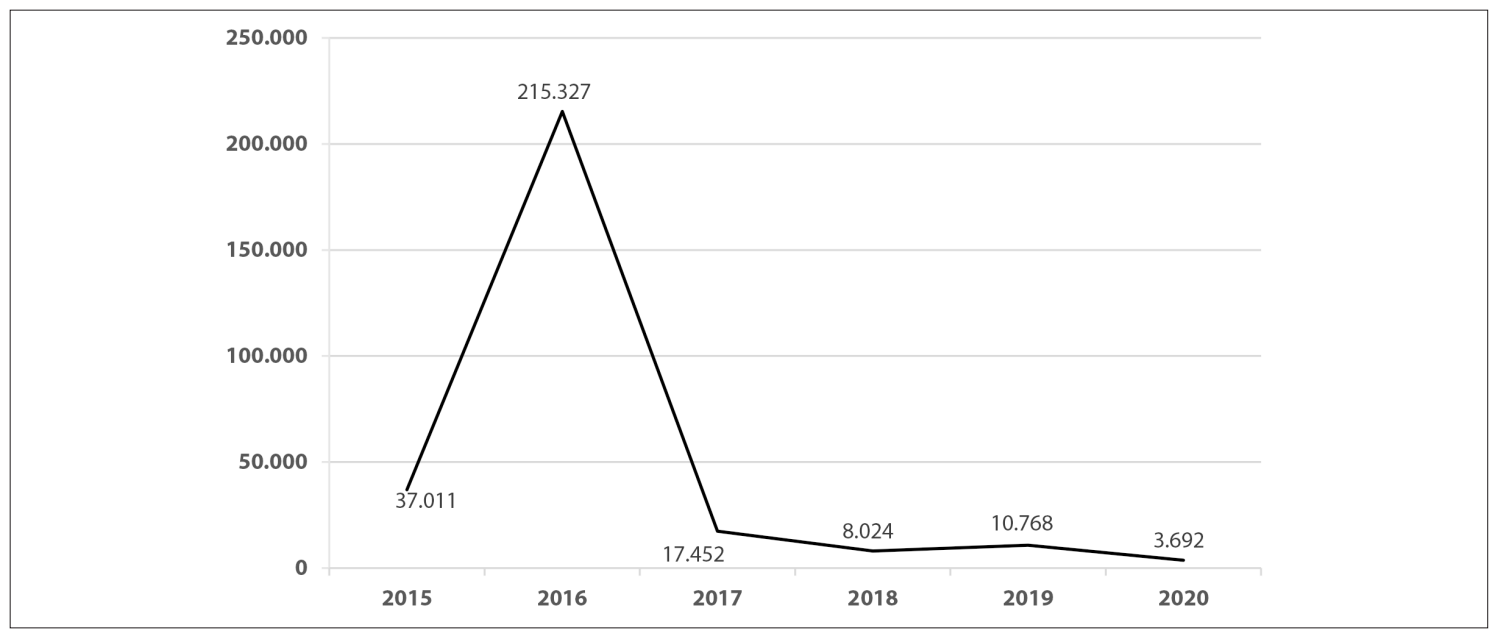

Fonte: Informações numéricas retiradas das referências 9, 10, 11 e 12. Figura 1 - Número de casos notificados de infecção pelo vírus Zika no Brasil, da Semana Epidemiológica 45 de 2015 até
a Semana Epidemiológica 23 de 2020

A transmissão sexual do vírus Zika foi sugerida em 2011 nos Estados Unidos da América, relatando o caso de uma mulher infectada pelo vírus quando seu parceiro retornou de viagem do Senegal em 2008, durante a qual foi infectado. ${ }^{23}$ Posteriormente, foi relatada a presença do RNA do vírus Zika em amostras de sêmen por mais tempo do que em amostras de sangue e urina em paciente apresentando hematospermia. ${ }^{24}$

Estudo realizado em Padova (Itália), de janeiro de 2016 a janeiro de 2017, demonstrou que o vírus Zika foi detectado em sêmen de cinco entre dez homens testados, com eliminação de até 370 dias e uma depuração média de 25 dias, No entanto, de forma geral, este período de eliminação viral é extremamente variável. ${ }^{28-30}$ Embora a detecção viral nos fluidos não signifique viabilidade para nova infecção, a transmissão sexual a partir de homem infectado está facilitada, visto que 0 sêmen apresenta maior carga viral e período mais prolongado de eliminação do que no soro e na urina. ${ }^{31}$ No entanto, há descrição de casos de transmissão sexual também a partir de mulher infectada para suas parceiras e parceiros sexuais. ${ }^{32}$ Também já foi demonstrada a transmissão do vírus Zika no relacionamento sexual passivo e ativo entre homens. ${ }^{21,33}$

\section{Aspectos clínicos}

A infecção pelo vírus Zika é descrita como uma doença febril aguda, autolimitada, com duração de três a sete dias, geralmente sem complicações graves.
A maior parte das infecções é assintomática, mas $20 \%$ a $25 \%$ das pessoas infectadas apresentam manifestações clínicas inespecíficas, sendo necessário realizar o diagnóstico diferencial laboratorial em relação à chikungunya e à dengue. ${ }^{34-39}$ Deve-se suspeitar da infecção na presença de dois ou mais dos sintomas descritos na Figura 2. A definição de caso suspeito é a mesma para pessoas residentes em áreas endêmicas e para viajantes procedentes dessas áreas, assim como para seus contatos de prática sexual sem proteção. ${ }^{25}$

Dentre todas as possíveis complicações em decorrência da infecção pelo vírus Zika, destacam-se aquelas ocorridas como desfechos gestacionais e as neurológicas. ${ }^{40}$ Mesmo em vista das imprecisões sobre a prevalência dessas complicações, visto que não se conhece a incidência real das infecções (considerando os assintomáticos), a associação causal entre as complicações gestacionais e neurológicas e a infecção pelo vírus Zika já foi cientificamente estabelecida. ${ }^{41-43}$ Considerando-se as complicações gestacionais, estima-se que as taxas de abortamento ( $1,2 \%$ a $3,9 \%)$, defeitos oculares $(1,0 \%$ a $7,5 \%)$, óbito fetal $(0,7 \%$ a $1,6 \%)$ e malformações $(3,1 \%$ a $22,8 \%)$ sejam aumentadas em decorrência da infecção durante a gravidez. ${ }^{35,44-46}$ A complicação neurológica mais temida em adultos é a síndrome de Guillain-Barré, cuja frequência estimada por estudos meta-analíticos varia de $0,01 \%$ a $1,23 \%$. ${ }^{47,48}$

Do ponto de vista reprodutivo masculino, nos casos em que 0 vírus atinge 0 testículo, aponta-se a agressão 


\begin{tabular}{|c|c|c|c|}
\hline Sinais e sintomas & Dengue & Zika & Chikungunya \\
\hline Febre (duração) & Acima de $38^{\circ} \mathrm{C}$ (4 a 7 dias) & $\begin{array}{c}\text { Sem febre ou subfebril } \leq 38^{\circ} \mathrm{C} \\
(1-2 \text { dias subfebril) }\end{array}$ & $\begin{array}{c}\text { Febre alta }>38^{\circ} \mathrm{C} \\
\text { (2-3 dias) }\end{array}$ \\
\hline Manchas na pele (frequência) & $\begin{array}{c}\text { Surgem a partir do quarto dia em } \\
30 \%-50 \% \text { dos casos }\end{array}$ & $\begin{array}{c}\text { Surgem no primeiro ou segundo dia } \\
\text { em } 90 \%-100 \% \text { dos casos }\end{array}$ & $\begin{array}{c}\text { Surgem em 2-5 dias } \\
\text { em } 50 \% \text { dos casos }\end{array}$ \\
\hline Dor nos músculos (frequência) & $+++/+++$ & $++/+++$ & $++++/++$ \\
\hline Dor articular (frequência) & $+/+++$ & $++/+++$ & Moderada/intensa \\
\hline Dor articular (intensidade) & Leve & Frequente e leve & Frequente e de moderado a intenso \\
\hline Edema da articulação \\
(frequência e intensidade)
\end{tabular}

Fonte: adaptado de Duarte et al. (2016), ${ }^{36}$ Secretaria Estadual de Saúde de Pernambuco (2015) ${ }^{37}$ e Duffy et al. (2009). ${ }^{39}$

Figura 2 - Frequência comparativa de sinais e sintomas mais comuns na infecção pelos vírus da dengue, Zika e chikungunya

do vírus Zika aos tecidos testiculares, cujo prognóstico dependerá da intensidade da resposta imune e inflamatória, podendo variar de simples redução reversível do número de espermatozoides até atrofia testicular. ${ }^{49,50}$ Avaliação realizada entre homens retornando de áreas endêmicas da infecção pelo vírus Zika para uma cidade europeia sem transmissão por mosquitos encontrou hematospermia macroscópica em 9,1\%, hematospermia microscópica em $81,8 \%$ e oligospermia em $60 \%$ deles. ${ }^{51}$

\section{Diagnóstico}

0 diagnóstico laboratorial durante a infecção aguda pelo vírus Zika se baseia na detecção do RNA viral pela reação em cadeia da polimerase, mediada por transcrição reversa (reverse transcription polymerase chain reaction, $\mathrm{RT}$-PCR) em soro ou sangue até sete dias após o início dos sintomas, ou em amostra de urina até 14 dias. Embora existam casos em que 0 RNA viral pode ser detectado por mais tempo, tanto no soro como na urina e no sêmen, essa possibilidade não colabora para o diagnóstico da fase aguda da doença. ${ }^{34}$

Nos casos de manifestações clínicas compatíveis com infecção pelo vírus Zika, com resultado negativo no exame diagnóstico por RT-PCR, ou se já transcorreram mais de sete dias desde o início dos sintomas, deve ser solicitado exame sorológico visando identificar imunoglobulina M (IgM) para o vírus Zika e para dengue. A IgM pode ser detectada, em média, a partir do $8^{\circ}$ dia, e a imunoglobulina $\mathrm{G}(\operatorname{IgG})$, a partir do $17^{\circ}$ dia após o início da infecção. Todo teste sorológico deve ser interpretado com cautela, visto o elevado número de reações cruzadas com outros Flavivirus. . $^{52,53}$

Se o resultado da sorologia for negativo para os dois vírus, descarta-se a infeção por ambos. Se algum dos dois for positivo, deve ser solicitado o teste por neutralização de redução de placas, se disponível. Se a redução for $>10$ para 0 vírus da dengue e $<10$ para 0 vírus Zika, confirma-se infecção por dengue. Se 0 resultado for $>10$ para 0 vírus Zika $\mathrm{e}<10$ para 0 vírus da dengue, confirma-se a infecção por vírus Zika. Se for $>10$ para os dois vírus, confirma-se infecção por Flavivirus e, se for $<10$ para os dois, descartam-se as duas infecções. ${ }^{34}$

Pela sobreposição de sintomas, em regiões de elevada prevalência das arboviroses, o diagnóstico diferencial da infecção pelo vírus Zika deve ser feito com todas as doenças exantemáticas, dentre elas chikungunya, dengue e sarampo. Em gestantes, 
obrigatoriamente amplia-se esse diagnóstico diferencial, considerando-se sífilis, toxoplasmose, rubéola, citomegalovírus e herpes (STORCH), todas elas com potencial de provocarem malformações fetais, ${ }^{36} \mathrm{am}$ pliada para Z-STORCH ao incluir as malformações provocadas pela síndrome congênita do vírus Zika.

\section{Tratamento}

Atualmente, não há tratamento específico para as infecções pelo vírus Zika. 0 manejo implica tratamento sintomático, que inclui hidratação, analgésicos e antipiréticos, devendo-se evitar os anti-inflamatórios não esteroidais até que o diagnóstico de dengue seja descartado. ${ }^{36}$ Esse princípio vale também para as gestantes. No caso de sequelas mais graves, como doenças neurológicas, deve haver acompanhamento médico para avaliar o tratamento adequado a ser aplicado, prioritariamente em centros especializados. ${ }^{40}$

\section{Vigilância, prevenção e controle}

A notificação dos casos suspeitos da infecção pelo vírus Zika é obrigatória para todos os estados do Brasil. A medida foi publicada no Diário Oficial da União por meio da Portaria $\mathrm{n}^{0}$ 204, de 17 de fevereiro de 2016. Todos os casos suspeitos também devem ser comunicados às autoridades de saúde, semanalmente. Para gestantes com suspeita de infecção pelo vírus ou de óbito suspeito, a notificação é imediata, ou seja, deve ser feita em até 24 horas. ${ }^{54}$

Um dos fatores que reforça a importância das medidas de profilaxia primária fundamenta-se na inexistência de vacina ou tratamento específico contra a infecção pelo vírus Zika e nem de métodos de prevenção secundária para a transmissão vertical. ${ }^{14}$ $\mathrm{Na}$ profilaxia primária, destacam-se 0 controle de criadouros de Aedes aegypti e o uso de repelentes e roupa apropriadas. Também se deve considerar que os mosquitos Aedes aegypti têm hábitos preferencialmente diurnos e são dependentes de claridade e temperaturas mais elevadas. ${ }^{55}$ Estratégias de controle biológico da população desses vetores têm se mostrado promissoras, como o uso da bactéria Wolbachia pipiensis, ${ }^{56}$ que interfere na reprodução do Aedes aegypti fazendo com que os ovos de fêmeas livres da infecção não eclodam quando forem fertilizados por um macho infectado por Wolbachia. ${ }^{57-59}$
Visando objetivamente ao controle da disseminação sexual do vírus Zika, deve-se reforçar a importância do uso do preservativo (feminino ou masculino) em todos os casos de possível exposição vetorial ou sexual em viagens a áreas de transmissão elevada e retorno a áreas não endêmicas, ou mesmo após infecção diagnosticada. ${ }^{21,30,60,61}$

Em termos de parcerias sexuais, é fundamental adotar medidas que reduzam a transmissão entre pessoas infectadas e desenvolver estratégias para diminuir a cadeia de transmissão, por meio da identificação e gestão adequada das parcerias sexuais. A comunicação de risco e a informação adequada aos usuários dos serviços de saúde são fundamentais. Uma abordagem diferenciada por gênero é importante, considerando que as respostas dos homens e das mulheres com relação à prevenção têm-se mostrado diferentes. A consciência sobre a doença está relacionada à atitude mais preventiva e protetora por pessoas de ambos os sexos. ${ }^{62}$

Segundo as orientações tanto dos Centros para 0 Controle e Prevenção e Doenças dos Estados Unidos da América quanto da Organização Mundial da Saúde, a quarentena de medidas sexuais protetivas ou abstenção sexual quando do retorno de viagens a regiões endêmicas é de 90 dias para 0 homem e de 60 dias para a mulher. Para o caso de parceiro de gestante que retorne de região endêmica da infecção pelo vírus Zika ou que tenha a infecção diagnosticada, esses organismos internacionais também partilham a orientação de sexo protegido ou até de abstinência sexual pelo tempo restante da gravidez. ${ }^{25,63}$ Essas orientações podem ser seguidas pelos profissionais brasileiros até que sejam incorporadas na próxima edição do PCDT.

\section{A infecção pelo vírus Zika durante a gestação}

A transmissão vertical do vírus Zika, a qual pode ocorrer em qualquer momento da gestação, tem sido associada a graves e deletérios desfechos gestacionais. Embora a frequência de transmissão vertical do vírus Zika entre gestantes assintomáticas seja difícil de ser mensurada, há confirmação de sua ocorrência. ${ }^{13}$ A persistência do RNA viral é mais prolongada entre gestantes, provavelmente devido à replicação viral na placenta, aumentando a exposição fetal e o risco de malformações congênitas até entre mães assintomáticas. ${ }^{64-66}$ 
0 espectro do acometimento do sistema nervoso central embrionário ou fetal causador de malformações e sua patogenia ainda não estão completamente estabelecidos. Sabe-se que o vírus Zika tem tropismo por células neurais progenitoras e que, no cérebro embrionário ou embrionário/fetal, ele interrompe 0 crescimento, a proliferação, a migração e a diferenciação de células neuronais, com graves consequências para o neurodesenvolvimento. ${ }^{40,44-46,67,68}$

Quando a infecção ocorre durante 0 primeiro e o segundo trimestres de gravidez, há maior risco de anormalidades estruturais do sistema nervoso central do embrião e do feto. Essas infecções apresentam mais frequentemente um quadro variado de alterações anatômicas, que resultam em ventriculomegalia, calcificações intracranianas e microcefalia. $13,14,35,69$

As alterações neonatais decorrentes da infecção pelo vírus Zika foram agrupadas sob a denominação de síndrome congênita do vírus Zika, incluindo a microcefalia com colapso do crânio, córtices cerebrais finos com calcificações subcorticais, desproporção facial, hipertonia, espasticidade, hiperreflexia, convulsões, irritabilidade, artrogripose, cicatrizes maculares, manchas focais da retina pigmentar, cegueira e perda neurossensorial da audição. ${ }^{67,70}$

A evolução da frequência de microcefalia como complicadora da gravidez no Brasil, entre os anos de 2015 e 2020, foi publicada no Boletim Epidemiológico da Secretaria de Vigilância em Saúde (Figura 3).$^{12} \mathrm{~A}$ medula espinhal também pode ser acometida, exibindo distorção arquitetural, perda neuronal grave e microcalcificações. ${ }^{64}$ No entanto, outras alterações também têm sido observadas em infecções ocorridas no terceiro trimestre da gravidez, mas detectadas tardiamente, às vezes após o nascimento, como defeitos oculares, disfagia, microcefalia, diminuição da acuidade auditiva, anormalidades eletroencefalográficas e convulsões, dentre outros agravos à saúde. ${ }^{45}$ Somente a prospecção das crianças expostas ao vírus Zika na vida intrauterina poderá subsidiar um entendimento mais ampliado da síndrome congênita do vírus Zika. ${ }^{70}$

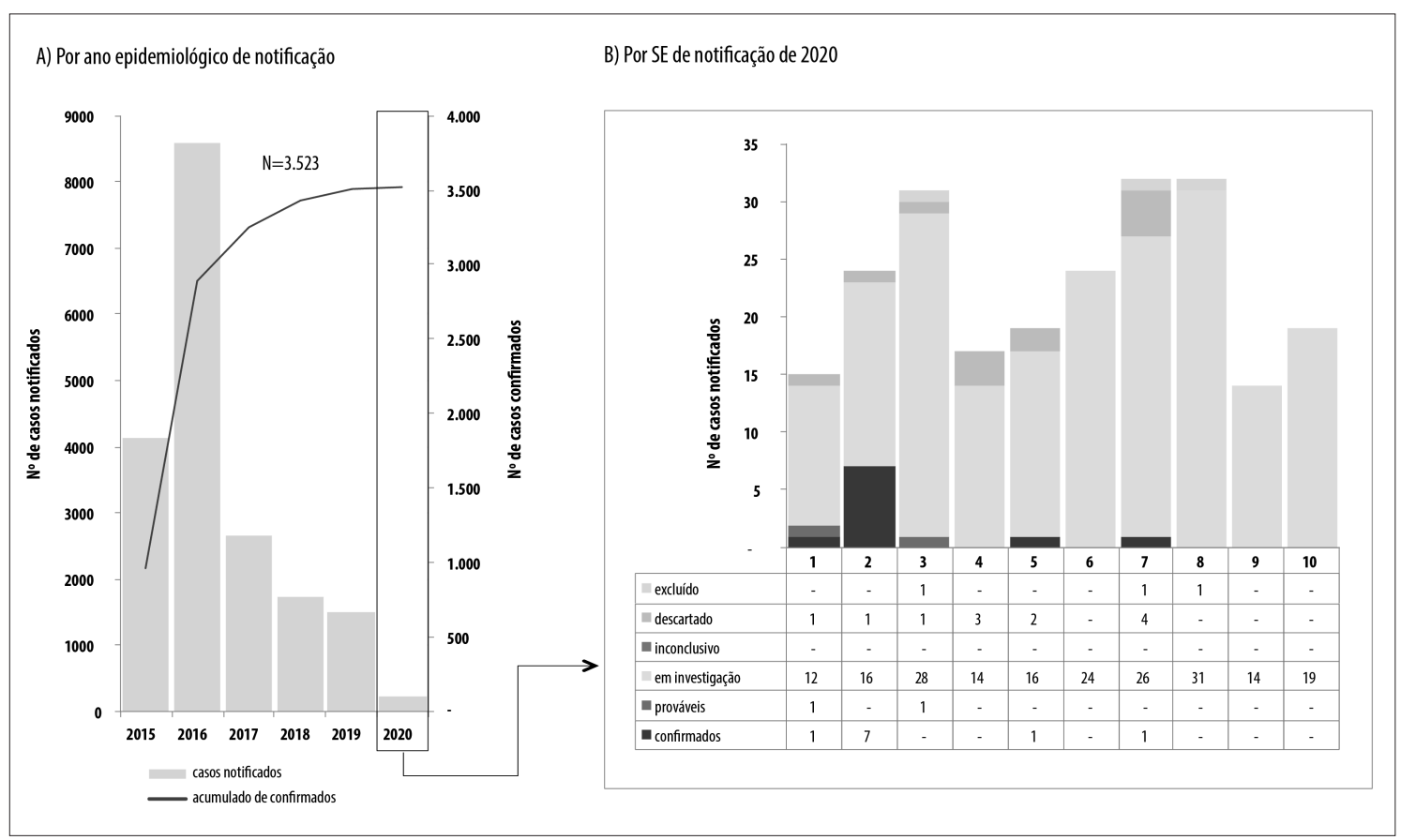

Fonte: Boletim Epidemiológico da Secretaria de Vigilância em Saúde, Ministério da Saúde. Dados atualizados em 09/03/2020.10

Figura 3 - Distribuição dos casos notificados de síndrome congênita do vírus Zika e outras etiologias infecciosas por ano epidemiológico de notificação (A) e por semana epidemiológica (SE) de notificação de 2020 (B), Brasil, 2015 até a SE 10 de 2020 


\section{Assistência pré-natal de baixo risco ou risco habitual (gestantes sem indícios de infecção pelo vírus Zika)}

Para as gestantes de baixo risco ou risco habitual, a estratégia mais importante referente ao vírus Zika é evitar que elas se infectem por esse vírus. Reafirmar medidas preventivas para a infecção pelo vetor ou por via sexual são as estratégias mais eficientes para evitar a propagação dessa infecção. ${ }^{13,54}$ Devem-se orientar as pessoas que não moram em áreas endêmicas a evitarem viagens a áreas onde a frequência da infecção pelo vírus Zika seja elevada. ${ }^{36,71}$

Do ponto de vista assistencial, após o surto epidêmico de infecção pelo vírus Zika, a Federação Brasileira das Associações de Ginecologia e Obstetrícia recomenda a implantação do exame ultrassonográfico em torno da $12^{\mathrm{a}}$ semana, de ultrassonografia morfológica em torno da $22^{a}$ semana e de um terceiro exame em torno da $32^{\mathrm{a}}$ semana. ${ }^{72,73}$ Esses exames visam à detecção precoce de alterações fetais decorrentes da infecção assintomática materna pelo vírus Zika. ${ }^{13,71}$

A triagem universal da infecção prévia por vírus Zika entre "gestantes assintomáticas", por meio de exames sorológicos, não é indicada. Torna-se fundamental considerar a baixa acurácia dos testes, os potenciais custos agregados e os escassos benefícios auferidos por essa medida. No caso de a sorologia ter resultado positivo, demonstrando a presença de anticorpos para o vírus, é preciso assegurar que não seja dada uma falsa impressão de segurança, o que poderia reduzir 0 cuidado da gestante em relação às outras arboviroses (dengue, chikungunya e febre amarela), doenças que também podem apresentar desfechos maternos e perinatais deletérios. ${ }^{73,74}$

Nos casos sugestivos da infecção pelo vírus Zika, a gestante deve procurar atendimento médico e submeter-se ao exame físico e laboratorial, na tentativa de orientar 0 diagnóstico. ${ }^{75}$ A Federação Brasileira das Associações de Ginecologia e Obstetrícia indica que, a partir da confirmação diagnóstica, a gestação seja considerada como de alto risco perinatal. ${ }^{73}$

\section{Assistência pré-natal para gestantes com diagnóstico de infecção pelo vírus Zika}

Uma grande demanda de suporte psicológico marca a assistência pré-natal de gestantes com diagnóstico de vírus Zika, sendo esta uma intervenção fundamental, além do cumprimento das orientações básicas do pré-natal, como o cuidado relacionado à pressão arterial e ganho de peso, nutrição adequada, exames laboratoriais rotineiros e vacinas. ${ }^{36,73}$

Atualmente, são conhecidas mais de 500 causas de microcefalia, além da infecção congênita pelo vírus Zika, com variados graus de gravidade. Considerando-se que a conduta de tratamento e acompanhamento da gestação, assim como da criança ao nascer, pode ser influenciada pela etiologia, destaca-se a importância da realização de exames diagnósticos para detectar 0 agente teratogênico. No caso da infecção pelo vírus Zika, a realização do RT-PCR do líquido amniótico obtido pela amniocentese pode ser uma alternativa para a realização do diagnóstico diferencial, ${ }^{13,73}$ considerando-se a possibilidade de resultados falso-negativos. ${ }^{62}$

Nos casos de acometimento fetal, a assistência pré-natal demandará cuidado com a vitalidade fetal por meio da cardiotocografia e ultrassonografia. A frequência de retornos dependerá de cada quadro clínico fetal, não havendo condições de protocolar intervalos rígidos entre as consultas. ${ }^{13,73}$

\section{Parto e amamentação}

De forma geral, mesmo as crianças acometidas pela síndrome congênita do vírus Zika suportam bem o trabalho de parto, considerando-se o parto vaginal como preferencial para as mães. ${ }^{71,73}$ Também se considera que 0 aleitamento natural seja 0 ideal para as crianças nascidas de mães portadoras da infecção pelo vírus Zika. Não havendo contraindicação de alimentação por via oral, estará liberada a amamentação. ${ }^{9}$

\section{Reprodução assistida}

Até 0 momento, não há casos descritos de transmissão vertical do vírus Zika decorrente de gravidez que tenham utilizado técnicas de reprodução assisti$\mathrm{da}$, mas se recomendam alguns cuidados para casais em tratamento para infertilidade. São eles: a) apresentar sorologia IgM negativa cinco dias antes do procedimento; b) aguardar até 90 dias após o aparecimento de sinais e sintomas relacionados à infecção pelo vírus Zika quando o homem foi infectado ou relate exposição sexual de risco ou viagem para regiões endêmicas dessa infecção; c) aguardar até 60 dias após sinais/sintomas relacionados à infecção pelo vírus Zika quando a mulher foi infectada ou relate exposição sexual de risco ou viagem para regiões endêmicas para essa infecção. ${ }^{25,63,75,76}$ 


\section{Contribuição dos autores}

Duarte G, Miranda AE, Bermudez XPD, Saraceni $\mathrm{V}$ e Martinez-Espinosa FE contribuíram com a concepção, delineamento, redação e revisão crítica do manuscrito. Todos os autores aprovaram a versão final a ser publicada e são responsáveis por todos os aspectos do trabalho, incluindo a garantia de sua precisão e integridade.

\section{Referências}

1. Brasil, Ministério da Saúde. Portaria ${ }^{\circ} 42$, de 5 de outubro de 2018. Torna pública a decisão de aprovar o Protocolo Clínico e Diretrizes Terapêuticas para Atenção Integral às Pessoas com Infecções Sexualmente Transmissíveis (IST) no âmbito do Sistema Único de Saúde - SUS. Diário Oficial da União, Brasília, DF, 8 out. 2018;194(Seção 1):88.

2. Dick GW, Kitchen SF, Haddow AJ. Zika virus. I. Isolations and serological specificity. Trans. R. Soc. Trop. Med. Hyg., 1952;46:509-520.

3. Macnamara FN. Zika virus: a report on three cases of human infection during an epidemic of jaundice in Nigeria. Trans. R. Soc. Trop. Med. Hyg., 1954;48:139-145.

4. Musso D, Gubler DJ. Zika virus. Clin. Microbiol. Rev., 2016;29(3):487-524.

5. Liu ZY, Shi WF, Qin CF. The evolution of Zika virus from Asia to the Americas. Nat. Rev. Microbiol., 2019;17(3):131-139. doi: 10.1038/s41579-018-0134-9.

6. Esser-Nobis K, Aarreberg LD, Roby JA, Fairgrieve MR, Green R, Gale M Jr. Comparative Analysis of African and Asian Lineage-Derived Zika Virus Strains Reveals Differences in Activation of and Sensitivity to Antiviral Innate Immunity. J. Virol.; 2019;93(13):e00640-19. doi: 10.1128/JVI.00640-19.

7. Hu T, Li J, Carr MJ, Duchêne S, Shi W. The Asian Lineage of Zika Virus: Transmission and Evolution in Asia and the Americas. Virol. Sin., 2019;34(1):1-8. doi: 10.1007/s12250-018-0078-2.

8. Borucki MK, Collette NM, Coffey LL, Van Rompay KKA, Hwang MH, Thissen JB, et al. Multiscale analysis for patterns of Zika virus genotype emergence, spread, and consequence. PLoS One, 2019;14(12):e0225699. doi: 10.1371/journal.pone.0225699.

\section{Agradecimento}

Os autores agradecem aos membros do grupo técnico de especialistas responsáveis pela elaboração do PCDT para Atenção Integral às Pessoas com IST em 2020 pela contribuição substancial para a realização deste trabalho.

9. Brasil. Ministério da Saúde. Secretaria de Vigilância em Saúde. Situação epidemiológica da infecção pelo vírus Zika no Brasil, de 2015 a 2017. Boletim Epidemiológico, 2018;49(47).

10. Brasil. Ministério da Saúde. Secretaria de Vigilância em Saúde. Monitoramento dos casos de arboviroses urbanas transmitidas pelo Aedes (dengue, chikungunya e zika), Semanas Epidemiológicas 1 a 52. Boletim Epidemiológico, 2018;49(59).

11. Brasil. Ministério da Saúde. Secretaria de Vigilância em Saúde. Monitoramento dos casos de arboviroses urbanas transmitidas pelo Aedes (dengue, chikungunya e zika), Semanas Epidemiológicas 1 a 52. Boletim Epidemiológico, 2020;51(02).

12. Brasil. Ministério da Saúde. Secretaria de Vigilância em Saúde. Monitoramento dos casos de arboviroses urbanas transmitidas pelo Aedes (dengue, chikungunya e zika), Semanas Epidemiológicas 1 a 23. Boletim Epidemiológico, 2020;51(24).

13. Duarte G, Moron AF, Timerman A, Fernandes CE, Mariani Neto C, Almeida Filho GL, et al. Infecção do vírus Zika em gestantes e microcefalia. Rev. Bras. Ginecol. Obstet., 2017;39(5):235-248.

14. Brasil. Ministério da Saúde. Secretaria de Vigilância em Saúde. Departamento de Vigilância de Doenças e Agravos Não Transmissíveis e Promoção da Saúde. Saúde Brasil 2015/2016: uma análise da situação de saúde e da epidemia pelo vírus Zika e por outras doenças transmitidas pelo Aedes aegypti. Brasília: Ministério da Saúde; 2017.

15. Miranda J, Martín-Tapia D, Valdespino-Vázquez Y, Alarcón L, Espejel-Nuñez A, Guzmán-Huerta M, et al. Syncytiotrophoblast of Placentae from Women with Zika Virus Infection Has Altered Tight Junction Protein Expression and Increased Paracellular Permeability. Cells, 2019;8(10):1174. 
16. Puerta-Guardo H, Tabata T, Petitt M, Dimitrova M, Glasner DR, Pereira L, et al. Zika Virus Nonstructural Protein 1 Disrupts Glycosaminoglycans and Causes Permeability in Developing Human Placentas. J. Infect. Dis., 2020;221(2):313-324.

17. Rosenberg AZ, Yu W, Hill DA, Reyes CA, Schwartz DA. Placental Pathology of Zika Virus: Viral Infection of the Placenta Induces Villous Stromal Macrophage (Hofbauer Cell) Proliferation and Hyperplasia. Arch. Pathol. Lab. Med.; 2017;141(1):43-48.

18. Simoni MK, Jurado KA, Abrahams VM, Fikrig E, Guller S. Zika virus infection of Hofbauer cells. Am. J. Reprod. Immunol., 2017;77(2):10.1111/aji.12613.

19. Musso D, Nhan T, Robin E, Roche C, Bierlaire $\mathrm{D}$, Zisou $\mathrm{K}$, et al. Potential for Zika virus transmission through blood transfusion demonstrated during an outbreak in French Polynesia, November 2013 to February 2014. Euro. Surveill., 2014;19.20761. doi: 10.2807/1560-7917.

20. Gourinat AC, O'Connor 0, Calvez E, Goarant C, Dupont-Rouzeyrol M. Detection of Zika virus in urine. Emerg. Infect. Dis., 2015;21(1):84-6.

21. Atkinson B, Hearn P, Afrough B, Lumley $\mathrm{S}$, Carter D, Aarons EJ, et al. Detection of Zika Virus in Semen. Emerg. Infect. Dis., 2016;22(5):940. doi: 10.3201/eid2205.160107.

22. Barzon L, Pacenti M, Berto A, et al. Isolation of infectious Zika virus from saliva and prolonged viral RNA shedding in a traveller returning from the Dominican Republic to Italy, January 2016. Euro. Surveill., 2016; 21:30159. doi: 10.2807/1560-7917.ES.2016.21.10.30159.

23. Foy BD, Kobylinski KC, Chilson Foy JL, Blitvich BJ, da Rosa AT, Haddow AD, et al. Probable non-vector-borne transmission of Zika virus, Colorado, USA. Emerg. Infect. Dis., 2011;17(5):880-2.

24. Musso D, Roche C, Robin E, Nhan T, Teissier A, Cao-Lormeau VM. Potential sexual transmission of Zika virus. Emerg. Infect. Dis., 2015;21(2):359-61.

25. World Health Organization. WHO guidelines for the prevention of sexual transmission of Zika virus. Geneva: World Health Organization; 2020 [citado em: ]. Disponível em: https://apps.who.int/iris/bitstream/ handle/10665/332466/9789241550482-eng.pdf.

26. Mead PS, Hills SL, Brooks JT. Zika virus as a sexually transmitted pathogen. Curr.
Opin. Infect. Dis., fev. 2018;31(1):39-44. doi: 10.1097/QC0.0000000000000414.

27. Counotte MJ, Kim CR, Wang J, Bernstein K, Deal CD, Broutet NJN, et al. Sexual transmission of Zika virus and other flaviviruses: a living systematic review. PLoS Med., 2018;15(7):e1002611. doi: 10.1371/journal. pmed.1002611.

28. Mead PS, Duggal NK, Hook SA, Delorey M, Fischer M, Olzenak McGuire D, et al. Zika Virus Shedding in Semen of Symptomatic Infected Men. N. Engl. J. Med., 2018; 378:1377-78.

29. Barzon L, Percivalle E, Pacenti M, Rovida F, Zavattoni M, Del Bravo P, et al. Virus and Antibody Dynamics in Travelers With Acute Zika Virus Infection. Clin. Infect. Dis., 2018;66:1173-1180.

30. Paz-Bailey G, Rosenberg ES, Doyle K, Munoz-Jordan J, Santiago GA, Klein L, et al. Persistence of Zika virus in body fluids: final report. N. Engl. J. Med., 2017; 379(13):1234-1243.

31. Calvet GA, Kara E0, Giozza SP, Bôtto-Menezes CH, Gaillard P, Franca RF, et al. Study on the persistence of Zika virus (ZIKV) in body fluids of patients with ZIKV infection in Brazil. BMC Infect. Dis., 2018;18(1):49. doi: 10.1186/s12879-018-2965-4.

32. Davidson A, Slavinski S, Komoto K, Rakeman J, Weiss D. Suspected Female-to-Male Sexual Transmission of Zika Virus - New York City, 2016. MMWR Morb. Mortal. Wkly. Rep., 2016;65:716-717.

33. Deckard DT, Chung WM, Brooks JT, Smith JC, Woldai S, Hennessey M, et al. Male-to-Male Sexual Transmission of Zika Virus - Texas, January 2016. MMWR Morb. Mortal. Wkly. Rep., 2016;65:372-4.

34. Sharp TM, Fischer M, Muñoz-Jordán JL, Paz-Bailey G, Staples JE, Gregory CJ, et al. Dengue and Zika Virus Diagnostic Testing for Patients with a Clinically Compatible Illness and Risk for Infection with Both Viruses. MMWR Recomm. Rep., 2019;68(No. RR-1):1-10.

35. Ximenes R, Ramsay LC, Miranda RN, Morris SK, Murphy K, Sander B; RADAM-LAC Research Team. Health outcomes associated with Zika virus infection in humans: a systematic review of systematic reviews. BMJ Open, 2019;9(11):e032275. doi: 10.1136/bmjopen-2019-032275.

36. Duarte G. Infecção pelo vírus Zika durante a gravidez. Femina, 2016;44:36-47.

37. Pernambuco (estado). Secretaria Estadual de Saúde. Secretaria Executiva de Vigilância em 
Saúde. Protocolo Clínico e Epidemiológico para investigação de casos de microcefalia no estado de Pernambuco. Versão n. 2. Pernambuco: Secretaria Estadual de Saúde; 2015. p. 1-42.

38. Lobkowicz L, Ramond A, Sanchez Clemente N, Ximenes RAA, Miranda-Filho DB, Montarroyos UR, et al. The frequency and clinical presentation of Zika virus coinfections: a systematic review. BMJ Glob Health. 2020;5(5):e002350. doi: 10.1136/bmjgh-2020-002350

39. Duffy MR, Chen TH, Hancock WT, Powers AM, Kool JL, Lanciotti RS, et al. Zika virus outbreak on Yap Island, Federated States of Micronesia. N. Engl. J. Med., 2009;360:2536-2543.

40. Pan American Health Organization. Epidemiological alert. Neurological syndrome, congenital malformations, and Zika virus infections. Implications for public health in the Americas. Washington, DC: Pan American Health Organization; 1 dez. 2015 [citado em: ]. Disponível em: https://www. paho.org/hq/dmdocuments/2015/2015-dec-1-cha-epi-alert-zika-neuro-syndrome.pdf.

41. Pomar L, Musso D, Malinger G, Vouga M, Panchaud A, Baud D. Zika virus during pregnancy: From maternal exposure to congenital Zika virus syndrome. Prenat. Diagn., maio 2019;39(6):420-430. doi: 10.1002/pd.5446.

42. Counotte MJ, Egli-Gany D, Riesen M, Abraha M, Porgo TV, Wang J, Low N. Zika virus infection as a cause of congenital brain abnormalities and Guillain-Barré syndrome: From systematic review to living systematic review. F1000 Res., 2018;7:196. doi: 10.12688/f1000research.13704.1.

43. Cranston JS, Tiene SF, Nielsen-Saines K, Vasconcelos Z, Pone MV, Pone S, et al. Association Between Antenatal Exposure to Zika Virus and Anatomical and Neurodevelopmental Abnormalities in Children. JAMA Netw. Open, 2020;3(7):e209303. doi: 10.1001/jamanetworkopen.2020.9303.

44. Nithiyanantham SF, Badawi A. Maternal infection with Zika virus and prevalence of congenital disorders in infants: systematic review and meta-analysis. Can. J. Public Health, 2019;110(5):638-648.

45. Coutinho M, Negrini SFBM, Araujo DCA, Teixeira S, Amaral F, Moro MC, Fernandes J, et al. Early maternal Zika infection predicts severe neonatal neurological damage: results from the prospective Natural History of ZIKA Virus Infection in Gestation (NATZIG) cohort study. Br. J. Obstet. Gynaecol. Artigo aceito. doi: 10.22541/au.159103608.85557750.
46. Sanchez Clemente N, Brickley EB, Paixão ES, Almeida MF, Gazeta RE, Vedovello D, Rodrigues LC, et al. Zika virus infection in pregnancy and adverse fetal outcomes in São Paulo State, Brazil: a prospective cohort study. Sci. Rep., 2020;10(1):12673. doi: 10.1038/s41598-020-69235-0.

47. Mier-Y-Teran-Romero L, Delorey MJ, Sejvar JJ, Johansson MA. Guillain-Barré syndrome risk among individuals infected with Zika virus: a multi-country assessment. BMC Med., 2018;16(1):67. doi:10.1186/s12916-018-1052-4.

48. Barbi L, Coelho AVC, Alencar LCA, Crovella S. Prevalence of Guillain-Barré syndrome among Zika virus infected cases: a systematic review and meta-analysis. Braz. J. Infect. Dis., 2018;22(2):137-141.

49. Almeida RDN, Braz-de-Melo HA, Santos IO, Corrêa R, Kobinger GP, Magalhaes KG. The Cellular Impact of the ZIKA Virus on Male Reproductive Tract Immunology and Physiology. Cells, 2020;9(4):1006. doi: 10.3390/cells9041006.

50. Tsetsarkin KA, Acklin JA, Liu G, Kenney H, Teterina NL, Pletnev AG, Lim JK. Zika virus tropism during early infection of the testicular interstitium and its role in viral pathogenesis in the testes. PLoS Pathog., 2020;16(7):e1008601. doi: 10.1371/journal.ppat.1008601.

51. Huits R, De Smet B, Ariën KK, Van Esbroeck M, Bottieau E, Cnops L. Zika virus in semen: a prospective cohort study of symptomatic travellers returning to Belgium. Bull. World. Health Organ., 1 dez. 2017;95(12):802-809. doi: 10.2471/BLT.17.181370.

52. Eppes C, Rac M, Dunn J, Versalovic J, Murray KO, Suter MA, et al. Testing for Zika virus infection in pregnancy: key concepts to deal with an emerging epidemic. Am. J. Obstet. Gynecol., 2017;216(3):209-225.

53. Ximenes RAA, Miranda-Filho DB, Brickley EB, Montarroyos UR, Turchi Martelli CM, Barreto-Araújo TV, et al. Zika virus infection in pregnancy: Establishing a case definition for clinical research on pregnant women with rash in an active transmission setting. PLoS Negl. Trop. Dis., 2019;13(10):e0007763.

54. Brasil. Ministério da Saúde. Portaria n ${ }^{0}$ 204, de 17 de fevereiro de 2016. Lista Nacional de Notificação Compulsória de doenças, agravos e eventos de saúde pública nos serviços de saúde públicos e privados em todo o território nacional. Diário Oficial da União, Brasília, DF, 18 fev. 2016 [citado em: ];32(Seção 1):23. Disponível em: https://bvsms.saude.gov.br/bvs/ saudelegis/gm/2016/prt0204_17_02_2016.html. 
55. Brasil. Ministério da Saúde. Combate ao Aedes Aegypti: prevenção e controle da Dengue, Chikungunya e Zika. Brasília: Ministério da Saúde, 2020 [citado em: ]. Disponível em: https://www. saude.gov.br/saude-de-a-z/combate-ao-aedes.

56. 0'Neill SL. The Use of Wolbachia by the World Mosquito Program to Interrupt Transmission of Aedes aegypti Transmitted Viruses. Adv. Exp. Med. Biol., 2018;1062:355-360.

57. Serbus LR, Casper-Lindley C, Landmann F, Sullivan W. The genetics and cell biology of Wolbachia-host interctions. Ann. ver. Genet., 2008;42:683-707.

58. Dutra HL, Rocha MN, Dias FB, Mansur SB, Caragata EP, Moreira LA. Wolbachia blocks currently circulating Zika virus isolates in Brazilian Aedes aegypti mosquitoes. Cell. Host. Microbe, 2016:771-774.

59. Caragata EP, Rocha MN, Pereira TN, Mansur SB, Dutra HLC, Moreira LA. Pathogen blocking in Wolbachia-infected Aedes aegypti is not affected by Zika and dengue virus co-infection. PLoS Negl. Trop. Dis., 2019;13(5):e0007443.

60. Deckard DT, Chung WM, Brooks JT, Smith JC, Woldai $\mathrm{S}$, Hennessey M, et al. Male-to-male sexual transmission of Zika virus - Texas, January 2016. MMWR Morb. Mortal. Wkly. Rep., 2016;65(14):372-4.

61. Oster AM, Brooks JT, Stryker JE, Kachur RE, Mead P, Pesik NT, et al. Interim Guidelines for Prevention of Sexual Transmission of Zika Virus — United States, 2016. MMWR Morb. Mortal. Wkly. Rep., 2016;65(5):120-1.

62. Jo S, Kim Y, Choi JS. Influencing factors on preventive health behaviours for Zika virus in pregnant women and their partners. J. Clin. Nurs., 2019;28(5-6):894-901.

63. Polen KD, Gilboa SM, Hills S, Oduyebo T, Kohl $\mathrm{KS}$, Brooks JT, et al. Interim guidance for preconception counseling and prevention of sexual transmission of Zika virus for men with possible Zika virus exposure - United States. MMWR Morb. Mortal. Wkly. Rep., 2018;67:868-871.

64. Ramalho FS, Yamamoto AY, da Silva LL, Figueiredo LTM, Rocha LB, Neder L, et al. Congenital Zika Virus Infection Induces Severe Spinal Cord Injury. Clin. Infect. Dis., 2017;65(4):687-690.

65. Reagan-Steiner S, Simeone R, Simon E, Bhatnagar J, Oduyebo T, Free R, et al. Evaluation of Placental and Fetal Tissue Specimens for Zika Virus Infection - 50 States and District of
Columbia, January-December, 2016. MMWR

Morb. Mortal. Wkly. Rep., 2017;66(24):636-643.

66. Venceslau EM, Guida JPS, Nobrega GM, Samogim AP, Parise PL, Japecangaet RR, et al. Adequate placental sampling for the diagnosis and characterization of placental infection by Zika virus. Front Microbiol., 2020;11:112. doi: 10.3389/fmicb.2020.00112.

67. van der Linden V, Filho EL, Lins OG, van der Linden A, Aragão MFVV, Brainer-Lima AM. et al. Congenital Zika syndrome with arthrogryposis: retrospective case series study. BMJ, 2016;354:i3899. doi: 10.1136/bmj.i3899.

68. Liang Q, Luo Z, Zeng J, Chen W, Foo SS, Lee SA, et al. Zika Virus NS4A and NS4B Proteins Deregulate Akt-mTOR Signaling in Human Fetal Neural Stem Cells to Inhibit Neurogenesis and Induce Autophagy. Cell. Stem. Cell., 2016;19(5):663-671.

69. Schuler-Faccini L, Ribeiro EM, Feitosa IML, Horovitz DD, Cavalcanti DP, Pessoa A, et al. Possible association between Zika virus infection and microcephaly - Brazil, 2015. MMWR Morb. Mortal. Wkly. Rep., 2016;65:59-62.

70. Moore CA, Staples JE, Dobyns WB, Pessoa A, Ventura $\mathrm{CV}$, Fonseca EB, et al. Characterizing the Pattern of Anomalies in Congenital Zika Syndrome for Pediatric Clinicians. JAMA Pediatr., 2017;171(3):288-295.

71. American College of Obstetricians and Gynecologists (ACOG). Management of Patients in the Context of Zika Virus: ACOG Committee Opinion, Number 784. Obstet. Gynecol., 2019;134(3):e64-e70.

72. Walker CL, Ehinger N, Mason B, Oler E, Little ME, Ohuma E0, Papageorghiou AT, et al. Ultrasound prediction of Zika virus-associated congenital injury using the profile of fetal growth. PLoS One, 13 maio 2020;15(5):e0233023. doi: 10.1371/journal.pone.0233023.

73. Federação Brasileira das Associações de Ginecologia e Obstetrícia. Infecção pelo vírus Zika e microcefalia. Comissão Especializada Provisória para o estudo do vírus Zika, gravidez e microcefalia. São Paulo, SP: Febrasgo, 2016 [citado em: ]. Disponível em: https://www.febrasgo.org.br/ media/k2/attachments/01-INFECCA0_PELO_VIRUS_ZIKA_EM_GESTANTES_E_MICROCEFALIA.pdf.

74. Charlier C, Beaudoin MC, Couderc T, Lortholary 0 , Lecuit M. Arboviruses and pregnancy: maternal, fetal, and neonatal effects. Lancet Child. Adolesc. Health, out. 2017;1(2):134-146. doi: 10.1016/S2352-4642(17)30021-4. 
75. Brasil. Ministério da Saúde. Secretaria de Vigilância em Saúde. Departamento de Doenças de Condições Crônicas e Infecções Sexualmente Transmissíveis. Protocolo Clínico e Diretrizes Terapêuticas para Atenção Integral às Pessoas com Infecções Sexualmente Transmissíveis [Internet]. Brasília: Ministério da Saúde; 2020 [citado em: ]. Disponível em: http://www.aids.gov.br/pt-br/pub/2015/ protocolo-clinico-e-diretrizes-terapeuticas-para-atencao-integral-pessoas-com-infeccoes.
76. Brasil. Ministério da Saúde. Agência Nacional de Vigilância Sanitária. Resolução RDC n ${ }^{0} 72$, de 30 de março de 2016. Altera a Resolução da Diretoria Colegiada RDC n ${ }^{0} 23$, de 27 de maio de 2011, que dispõe sobre o regulamento técnico para 0 funcionamento dos Bancos de Células e Tecidos Germinativos e dá outras providências. Diário Oficial da União, DF, 1 abr. 2016 [citado em: ];62(Seção 1):103. Disponível em: http://portal.anvisa.gov. br/documents/10181/2718376/RDC_72_2016_. pdf/7283a105-bb94-4a6c-a3d6-ca69f8563dff.

\section{Abstract}

This article addresses vector, sexual and vertical transmission of Zika virus, a topic covered in the Clinical Protocol and Therapeutic Guidelines for Comprehensive Care for People with Sexually Transmitted Infections, published by the Brazilian Ministry of Health in 2020. Although in Brazil Zika virus is transmitted most predominantly by Aedes aegypti, the vertical and sexual transmission routes are of significant importance for reproductive health. Sexual transmission demands the use of specific prophylactic interventions, including the use of male or female condoms, especially among couples planning pregnancy. Vertical transmission is linked to severe structural abnormalities of the central nervous system and there is still no vaccine or known pharmacological resources that can prevent it. As the disease is predominantly asymptomatic, failure to comply with basic principles of care and guidelines related to the spread of infection transcends the severity of the symptoms of the disease.

Keywords: Zika Virus; Sexually Transmitted Infections; Vertical Transmission; Microcephaly; Congenital Abnormality; Disease Prevention.

\section{Resumen}

Este artículo aborda la transmisión vectorial, sexual y vertical del virus Zika, tema tratado en el Protocolo Clínico y Directrices Terapéuticas para la Atención Integral a Personas con Infecciones de Transmisión Sexual, publicado por el Ministerio de Salud de Brasil en 2020. Aunque en Brasil el virus Zika sea principalmente transmitido por Aedes aegypti, las vías vertical y sexual de transmisión son de gran importancia para la salud reproductiva. La transmisión sexual exige el uso de intervenciones profilácticas específicas, incluido el uso de condones masculinos o femeninos, especialmente entre las parejas que planean un embarazo. La transmisión vertical está ligada a graves anomalías estructurales del sistema nervioso central y todavía no existe una vacuna o recursos farmacológicos conocidos que puedan prevenirla. Como la enfermedad es predominantemente asintomática, el incumplimiento de los principios básicos de atención y las pautas relacionadas con la propagación de la infección trasciende la gravedad de los síntomas de la enfermedad.

Palabras clave: Virus Zika; Infecciones de Transmisión Sexual; Transmisión Vertical; Microcefalia; Anormalidad Congénita; Prevención de Enfermedades.

Recebido em 25/07/2020

Aprovado em 19/10/2020 